\title{
Knowing how and pragmatic intrusion ${ }^{1}$
}

\author{
ALESSANDRO CAPONE
}

\begin{abstract}
It will be argued that "knowing how" can be reduced to "knowing that" provided that a view based on pragmatic intrusion is accepted. In this paper, I explore various interconnected ideas: opacity, Gettier's problem, Igor Douven's pragmatics of belief, negativity arguments, and contextualism about knowledge. This paper mainly shows that philosophy and pragmalinguistic considerations are deeply entangled. When matters of inference are considered, it is also worthwhile considering pragmatic intrusion. There are reasons to believe that almost all questions that pertain to knowing how can be analyzed with reference to pragmatic intrusion - that being a pervasive feature of human communication. Given what Igor Douven says about the pragmatics of belief, we are not surprised that knowledge, as well as belief, is strictly connected with the notion of communication and that many of the arguments that pertain to the sphere of epistemology can be illuminated by the tool of pragmatic intrusion.
\end{abstract}

\section{Introduction}

I start this paper with some programmatic statements. We have seen how Grice's pragmatics was assimilated and put to use by linguistics in the course of this and the previous century. The assimilation of Grice's ideas almost amounted to a revolution and spurred an enormous amount of work on this topic. However, now the time has come for a new period of research, in which Grice's philosophical ideas are applied (back) to philosophical topics. We have sufficient evidence showing that this can be done successfully (see for example the brilliant paper by Douven 2009). The quantity of work on propositional attitudes and pragmatics indicates that this type of program can be successfully executed and should, therefore, be executed. It would not be a bad idea to extend the topics to which we can apply our ideas about pragmatic intrusion and 
explicatures. I am persuaded that knowing how is one such topic in which pragmatics can be applied to philosophy in the attempt to resolve a philosophical problem. However, since "knowing how" attribution is also a linguistic practice, we should also find some harmony between philosophical and linguistic descriptions. It is, therefore, natural to want to explain a number of inferences triggered by knowing how utterances in terms of pragmatics.

In this paper I shall deal with the pragmatics of knowing how utterances. Since "knowing how" vs. "knowing that" has received detailed treatment in the philosophical literature (see Fantl 2009 for a good review), we cannot but pay attention to what philosophers have said. However, in the main, I want to stress what is needed for a theory of communication, rather than a theory of knowledge. Since a theory of knowledge and a theory of communication intersect at various points, this is not easy to do. For example, one reason why we utter sentences such as "John knows that p" is to inform the hearer that p. Hearing a sentence like "John knows that $p$," the hearer is entitled to infer that $p$, provided that he trusts me and he trusts John. Nevertheless, I assume that epistemology and a theory of communication are different projects, with different aims, and it does no harm to reveal my bias toward a theory of communication. In starting this paper, my hope is that we shall shed light on pragmatic inferential processes involved in understanding apparently simple "knowing how" utterances. Essentially, I want to reflect on what is being communicated and on what inferential processes are triggered when "knowing how" utterances are proffered. I will claim that such inferential processes are responsible for what is being communicated at a truth-conditional level.

Indirectly, my inferential approach serves to throw light on many problems that bear on the distinction between "knowing how" and "knowing that" and on the possibility of reducing "knowing how" to "knowing that." My inferential approach shows that, despite recalcitrant data leading to the opposite view, the right interpretation of these data will, in fact, lead to the idea by Stanley and Williamson that knowing how is a species of knowing that.

I start the paper with the exposition of Stanley and Williamson's (2001) paper according to which ' $\mathrm{X}$ knows how to $\mathrm{p}$ ' must be analyzed as ' $\mathrm{X}$ knows that there is a way $w$ and that he can $p$ in this way.' I then move on to the discussion of opacity, which has been claimed to constitute another reason for the asymmetry between knowing how and knowing that. I argue that opacity characterizes both knowing how and knowing that and answer some objections. I also discuss an objection to Stanley and Williamson's treatment of Gettier's problem. My analysis is that knowing how can be Gettiered. I then consider objections by Sgaravatti and Zardini to an assimilation of knowing how to knowing that based on negativity arguments. I argue that these objections are not well-founded and can be dissolved through pragmatic intrusion. Subsequently, I discuss knowing how and modularity of the mind, and claim 
that modular considerations need not be inimical to a unified treatment of knowing how à la Stanley and Williamson. I argue that the considerations on contextualism and knowledge by Keith De Rose are also applicable to knowing how, in addition to knowing that. I also argue that Igor Douven's considerations on the pragmatics of belief apply to knowing how as well as to knowing that.

In Part 2, I present a brief section on the notion of pragmatic intrusion, which will be of help in understanding the issue of knowing how. I provide some of the standard examples of pragmatic intrusion. Then, I deal with a number of uses of the "knowing how" construction, and I focus, among other things, on the asymmetry between knowing that and knowing how, noticed by Snowdon. While one can deduce 'I know that p' from 'X knows that p,' it is not clear that one can deduce 'I know how to $\mathrm{p}$ ' from 'X knows how to p.' In section 2.2, I consider a famous objection by Rumfitt to Stanley and Williamson's treatment and claim that it can be dissolved through pragmatic intrusion. In section 2.3, I consider various inferences in context and also argue in favor of pragmatic intrusion, considering a weak form of contextualism. I also consider interpretative problems with quantifiers and implicit arguments. In section 2.4, I argue in favor of a unified treatment of knowing how and knowing that, through pragmatic intrusion. I consider two alternative hypotheses.

\subsection{Stanley and Williamson on knowing how}

Stanley and Williamson (2001) question Ryle's (1949) considerations on the distinction between knowing how and knowing that, a distinction that has engaged many philosophers of mind and of language. In addition to this, they question Ryle's claim that an action of any kind requires a previous act of thinking, to count as intelligent. In this paper, I will not dwell on this second and important issue, but I will concentrate on whether knowing how can be subsumed into knowing that. Stanley and Williamson question Ryle's distinction on the basis of linguistic arguments - a move that has caused Michael Devitt's perplexity, since he claims that metaphysic claims should be settled by metaphysic arguments (Devitt, forthcoming). Yet, it is not true that Stanley and Williamson simply deal with the linguistics of "knowing how"; they also deal with various connected phenomena that are typical of propositional attitudes (e.g., Gettier's problem; the opacity problem). It simply turns out that many of the problems encountered in the discussion of the distinction between knowing how and knowing that can be resolved - if not dissolved - through the recognition of pragmatic intrusion. In this paper, I claim that one cannot understand the issue of knowing how independently of the understanding of the phenomenon of pragmatic intrusion. 
So I am sympathetic in principle to Stanley and Williamson's (2001) "linguistic" treatment of knowing how, since linguistics and philosophy in this case intersect to a greater extent than in a number of different issues.

To make complex things simple, Stanley and Williamson take cases of "knowing how" to be cases of indirect questions (embedded questions). ${ }^{2}$ In this perspective, a sentence such as "Ann knows how to ride the bike" has the same truth-conditions as "Ann knows that there is a way w, which is a way for Ann to ride the bike.' To be more explicit, this must be interpreted as 'Ann knows that there is a way w such that she can ride the bike in way w.' This proposal admits three kinds of pragmatic intrusion: (1) assigning the "some rather than all" interpretation to the knowing how sentence (i.e., Ann knows some way (not all ways) which is a way for her to ride the bike); (2) assigning a deontic modal interpretation to the infinitival construction (i.e., Ann knows how to drive the bike $\rightarrow$ Ann knows there is a way w such that she can ride the bike in way w); and (3) assignment of a "de se" interpretation to PRO (i.e., Ann knows that $\mathrm{w}$ is a way for her to ride the bike, NOT Ann knows that $\mathrm{w}$ is a way for one to ride the bike; I will return to this point later on).

The proposal becomes more complicated when it comes to modes of presentation. In line with considerations about propositional attitudes, given that "know" is like "belief" in giving rise to opacity problems, one had better introduce the notion of modes of presentation of the reference. The reference can present itself to the knower in different ways. To account for the cases in which knowing how is equivalent to having a skill, Stanley and Williamson introduce the notion of a practical mode of presentation. (In addition to being told how to p, you can be shown how to $\mathrm{p}$.)

\subsection{Opacity}

Those who want to emphasize the contrast between knowing how and knowing that typically invoke two characteristics of knowledge claims: opacity and Gettier's problem (Gettier 1963). Knowledge claims are typically opaque; in other words, substitutability of identicals (Leibniz's law) does not work inside the scope of a knowledge/belief operator. Suppose that Elizabeth = the Queen of England. Then in a sentence such as (1)

(1) Elizabeth greeted the Polish ambassador.

one can replace "Elizabeth" with "The Queen of England" without changing the truth conditions of the sentence. However, in a sentence such as (2)

(2) Mary knows that Elizabeth greeted the Polish ambassador.

one cannot freely replace "Elizabeth" with "The Queen of England" (in case Elizabeth = the Queen of England) UNLESS one also knows that Mary knows 
that Elizabeth = the Queen of England. After Natahn Salmon (1990), one tends to interpret opacity pragmatically. Truth-conditionally, the sentence "Mary knows that Elizabeth greeted the Polish ambassador" is the same as the sentence "Mary knows that the Queen of England greeted the Polish ambassador," however they differ in the implicated import. Someone who utters (2) somehow commits herself to accepting that Mary knows Elizabeth through the mode of presentation "Elizabeth" and NOT through another mode of presentation. Thus, she might not accept that Mary knows Elizabeth under the mode of presentation "The Queen of England" and, therefore, she might not accept the statement (3)

(3) Mary knows that the Queen of England greeted the Polish ambassador.

Those who want to say that knowledge-how and knowledge-that claims are completely different have the opportunity to deny that opacity applies to knowledge-how. Suppose that John regularly attends some karate classes and knows how to make a move that involves three steps. Let us suppose that there is also a type of dance - let us call it the Cuckoo dance - that involves these three steps. Then we should describe John, who knows how to practice karate, as someone who knows how to engage in the Cuckoo dance. Yet, he would hardly be willing to describe himself as someone who can practice the Cuckoo dance. He would answer negatively the question whether he can practice the Cuckoo dance. But why should it matter whether John is willing to accept that he can practice the cuckoo dance? We know that, if we bothered to explain to him, what the cuckoo dance is like, he would be able to do it.

There does, therefore, "prima facie" appear to be an asymmetry between knowing that and knowing how. When we come to knowing that, the subject's judgments about what he knows are important. After all, usually one knows that he knows that $p$ (but see Williamson 2002 for the claim that one who knows $p$ need not know that he knows $p$ ). If the subject's judgments are important, then one hardly knows that $p$ UNLESS one knows that he knows that $p$ and, if $p$ is presented under a different mode of presentation, the risk is there that the subject will not accept that he knows that $p$ under mode of presentation $\mathrm{q}$, because he has introspective access to his knowledge state and he does not find there the proposition $\mathrm{q}$.

Now, the contrast between knowing how and knowing that, in terms of opacity, seems to depend on two facts: luminosity; and pragmatic intrusion. Concerning luminosity, I am inclined to say, following Williamson (2002), that not in all cases in which one knows $p$ one knows that one knows $p$, albeit normally luminosity is implied. Concerning pragmatic intrusion, we must remember that opacity was heavily dependent on that. There may be pragmatic reasons why pragmatic intrusion occurs to a greater extent in knowing that claims than in knowing how claims. Knowing how claims, in fact, are normally 
connected with practical problems. Why do I know whether John knows how to $\mathrm{p}$ ? Presumably I want to know whether John knows how to $\mathrm{p}$ because I need to $\mathrm{p}$. And if I know that John knows how to $\mathrm{q}$ and that knowing how to $\mathrm{q}$ is equivalent to knowing how to $\mathrm{p}$, then I can use John's know how for the purpose of resolving my practical problem. Knowledge that claims, on the contrary, are not connected with practical problems, but with inferential knowledge. Often I need to know that $\mathrm{p}$, because $\mathrm{p}$, together with $\mathrm{q}$, tells me whether $\mathrm{n}$, and I need to know whether $\mathrm{n}$ is true in order to do F. (And I can know $\mathrm{p}$ if I know that John knows that p). Opacity is clearly a problem in inferential knowledge, since it is a limit to what can be inferred given a knowledge claim. Surely it would be of help to me to know that Mary knows that the Queen of England will be here today-I would know that there is a likelihood that the traffic will be jammed and I will avoid driving in the city center. Yet, there is no way to extract this information from knowledge that Mary knows that her friend Elisabeth will be here today.

So, my conclusion is that knowing that and knowing how behave differently with respect to opacity not because they are inherently different claims, but because they serve different purposes. It is the function of the claims that makes them appear as if they were different with respect to opacity.

\subsection{Gettier's problem}

Many have found it reasonable to assume that if knowing how is not completely different from knowing that, then it is vulnerable to Gettier's problem. In short, Gettier's problem consists of the fact that a proper knowledge claim must not admit devious types of justification. For instance, the following case does not count as knowledge.

John sees Billy drive a new Mercedes. He concludes that he is the owner of a new Mercedes. Thus, he is able to make the inference that either Billy or Fred bought a new Mercedes. It then turns out that Fred bought a new Mercedes, but Billy didn't (he was simply trying Fred's car). Then by pure luck, it is true that Fred bought a new Mercedes; hence it is true that either Fred or Billy bought a new Mercedes. John believed that either Fred or Billy bought a new Mercedes; he was somehow justified in coming to that belief. So should we say that he knew that Fred or Billy bought a new Mercedes? The standard answer has been negative and epistemologists have pondered on the nature of the justification. In short, the justification must be non-devious.

Now, can knowing how claims be Gettiered? Stanley and Williamson (2000) answer this question positively. Suppose that John wants to learn how to fly a plane and does this through a flight simulator. Wicked Fred changes the simulator's programs intending to disorient John, thus preventing him from learning how to fly a plane. Yet, despite his evil intentions, by mere luck, the simula- 
tor activates the right programs, designed to train a learner how to fly a plane. When he finishes his simulation courses, John is actually able to fly a plane, and everyone admires him for his skill. Should we say that he knows how to fly the plane? If he knows how to fly a plane, he knows that by mere luck. Surely the success is fortuitous and even if AFTER he actually proves that he is able to fly a plane, we are willing to grant him know-how, we would be reluctant to let him fly a plane if we knew what evil Fred has done to the simulator. After seeing what Fred has done to the simulator, we would predict that John would not be able to fly the plane. We would not be willing to let him fly the plane because we think he has not acquired know-how.

It has been objected (Poston 2009) that, appearances notwithstanding, John has know-how. He knows how to fly the plane, and that is all that matters to show that knowing how cannot be Gettiered. Yet, it would be reasonable to suppose that when John knows how to fly a plane, he knows all the kinds of steps involved in flying a plane, and he knows of all ways $w$ in which one can fly a plane, that w is a way for him to fly the plane. How can he know that w is a way for one to fly the plane if he learned that $\mathrm{w}$ is a way to fly the plane through an evil instructor? If knowing how has to be learned, it must be learned in the proper way. The case is analogous to knowing that. Suppose that Mary tells me that Fred is in Paris. Fred happens to be in Paris. Yet Mary was evil enough to tell me a lie. Did I really know that Fred was in Paris? The justification for my belief was devious, thus I did not really know. In the same way, when an evil instructor tells me (or shows me) that $\mathrm{w}$ is a way to fly a plane, hoping to induce me to make a mistake and, unaware to him, w proves to be an efficient way to fly the plane, then it is by mere luck that I can fly the plane, as my justification for believing that $\mathrm{w}$ is a way for me to fly the plane was devious.

\subsection{Sgaravatti and Zardini against the assimilation of knowing how to knowing that}

Before moving on to a deeper treatment of knowing how vs. knowing that, I would like to consider some interesting objections by Sgaravatti and Zardini (2008) to subsuming knowing how into knowing that. The objections are intelligent and worthwhile discussing. The analysis according to which knowing how is subsumed into knowing that, following Stanley and Williamson, amounts to more-or-less the following:

John knows how to ride the bike $=$ def John knows that there is a way $\mathrm{w}$ which is a way to ride the bike.

This analysis is still incomplete, in that it requires the introduction of a modal element, but this will not change the gist of our discussion. 
Now, Sgaravatti and Zardini argue against Stanley and Williamson on the basis of negativity. Consider

(4) John knows how to square the circle.

Translated through Stanley and Williamson's semantics, this would come to:

(5) John knows the answer to the question how he can square the circle

or

(6) John knows that $\mathrm{w}$ is an answer to the question how he can square the circle.

However, Sgaravatti and Zardini argue, John knows a perfect answer to the question how to square the circle and that is 'In no way!', but nevertheless he cannot square the circle. When the negativity argument is introduced, Stanley and Williamson's treatment faces a serious problem.

If I were Stanley and Williamson, I would not be worried by the negativity problem. I assume their answer would be that if one answers "In no way!" to the question how to square the circle, then one has no answer to the question how to square the circle.

If you were to ask me to make eight loaves of bread out of just two loaves, or how one can make eight loaves of bread out of just two loaves, I would not be able to provide a satisfactory answer to your question. Knowing how involves providing a satisfactory answer to a (practical) question, and not just an answer whatsoever. If providing an answer whatsoever to the question how I can drive a powerful motorbike is what enables me to drive a motorbike, then, I (who cannot ride a powerful motorbike) could qualify as knowing how to drive a powerful motorbike. But it is not an answer whatsoever, that is required, but an answer that allows me to carry out a task. In Sgaravatti and Zardini's case, could we honestly say that the answer "In no way!" provides a satisfactory answer to the question how to square the circle? If it does not, then we should not be surprised if one cannot manage to square the circle, even if one is able to provide an answer (which turns out to be inadequate).

If anything, Sgaravatti and Zardini's contribution is to clarify what is or must be intended when one says that $\mathrm{w}$ is the answer to a question. Presumably, the notion of Relevance (à la Sperber and Wilson 2004) may be of help. Relevance is defined (by Sperber and Wilson) in terms of contextual effects and processing efforts. There are three ways in which a newly presented piece of information may interact with the context to yield a contextual effect: (1) it may combine with contextual assumptions to yield a contextual implication (that is, a logical implication derivable neither from the contextual assumptions nor from the new information alone); (2) it might strengthen an existing 
assumption; and (3) it may contradict and lead to the elimination of an existing assumption.

Now, let us reconsider the question whether the answer "In no way!" is relevant to the question "How can one square the circle?" Does this answer create cognitive effects that justify the effort of vocalizing it? Well, one thing the answer does, surely; that is, it questions the question and categorizes it as a question that cannot be answered. But then "In no way!" is NOT an answer to the question, but a challenge to the question, amounting to, more or less, "Why did you ask me such an absurd question?" Then, if it is not an answer to the question, it is not in conflict with the fact that nobody actually possesses this know-how. I assume Relevance Theory - and in general theories about communication - has a role to play in clarifying this not uninteresting case posed by Sgaravatti and Zardini. At this point, I ask whether the one we have just encountered is a case of pragmatic intrusion. Pragmatic intrusions are cases in which a pragmatic inference allows truth-evaluability. If I remember well, the cases of pragmatic intrusion discussed by Carston (1999) were exactly cases in which, unless pragmatic intrusion was posited, one ended up with a logical form that could lead to contradictory interpretations. Consider one of those examples:

(7) If the King of France died and France became a republic, I would be happy; but if France became a republic and the king of France died, I would be unhappy.

There is, in this sentence, a potential for contradiction, if only truth-conditional elements of meaning deducible from semantics are considered. However, in context the sentence is NOT contradictory, provided that the right temporal relations are assigned at the level of the utterance. In Sgaravatti and Zardini's case, we have a potential contradiction:

(8) John knows the answer to the question how to square the circle - "In no way"- - but he does not know how to square the circle.

However, once pragmatic intrusion is considered, and the pragmatics overrides the semantics of 'John knows the answer to the question how to square the circle: "In no way!" by yielding the interpretation 'John challenged the question how to square the circle as absurd,' the contradiction which Sgaravatti and Zardini called our attention to disappears. We should not be surprised that this happens, as this is in line with many cases of pragmatic intrusion.

The case of 'In no way!' given as a reply to the question whether one can square the circle is clearly a case of metalinguistic negation. Metalinguistic negation, according to Horn (1985: 134) is a means for objecting to a previous utterance on any grounds whatsoever. In our case, however, the utterance is an 
answer to a question, not to a statement, and thus it is challenge to the (reasonableness) question.

\subsection{Knowing how and modularity of mind}

Now I address a different issue, which has a theoretical bearing on our decision to treat know-how and theoretical knowledge as distinct or, otherwise, as unified. It has been claimed in the literature that knowledge how and knowledge that belong to different modules of the brain. There are studies on dissociations between knowing how and knowledge-that. (For a review, see Williams 2009 and Young 2004; for a detailed treatment of the distinction between declarative and procedural knowledge, see Devitt, forthcoming). An amnesic patient can lose her knowledge that without losing her knowledge how. This is amazing to say the least. To those who are not persuaded, consider what happens when I am on the speedway and without seeing the car in front of me I suddenly stop my car. I am amazed. I know that I did not see that car, but I stopped my car nevertheless. It is NOT a miracle occurring or an angel that continuously assists me. We have a dual visual system, one of which is specialized in seeing objects, the other being specialized in knowledge-how. I was not involved in an accident because one visual system specialized in motion orientation was able to orient my motion path and to block it. In other words, I know how to drive my car in the speedway, even if I do not see the car in front of me (say, I am distracted by intense thoughts about something else).

Now, I do not want to take issue with this type of argument and claim that it is wrong. But I would like to know what it shows. Does it show that there is no connection between knowing how and knowing that? Is not an expert driver able to articulate his know-how and put that into writing a manual on how to drive a car? Analogously, cannot a man who lives by buying shares on the stock exchange articulate his tacit know-how and write a book on how to make investments? Assuming that there are different compartments in the mind for techniques and strategies, for skill know-how and articulated know-how, is it impossible to argue that a certain knowledge-that claim (tacit or overt) is associated with a practical mode of presentation that resides in the knowledge how module?

Surely a knowledge-how claim could be minimal. A person who knows how to drive the car can minimally have knowledge-that by knowing that $\mathrm{w}$ is a way of answering the question how to drive the car, while storing the practical mode of presentation with which $\mathrm{w}$ is associated in a different module of the brain. Such a minimal knowledge-that is not impossible. Stanley and Williamson's claims are not incompatible with the current theories on the modularity of mind, since they can allow that practical modes of presentation can be stored in a module that is reserved for know-how. 


\subsection{Knowing how and contextualism}

Now I will address the problem of epistemic contextualism. Assuming that contextualism à la Keith De Rose (2009) has its validity (one can accept it fully or in part), how does the bifurcation between knowing how and knowing that fare in the light of contextualism?

Contextualism in epistemic philosophy is the claim that the same knowledge claim can have different truth conditions in different contexts. The utterance

(9) Mary knows that the bank is open on Saturday.

may be true or false depending on the situation of utterance. In a low-stake situation, the claim may be true, while in a high-stake situation the claim may be false. Can this be applied to knowing how claims too? Intuitively, one would say that contextualism provides the strongest objection to the propositional view of knowing how (i.e., How can skill cases of know-how be sensitive to low and high stakes situations?). Yet, on a pondered analysis, this is not the case. Consider the situation in which John is asked to open the safe, which is connected with an explosive device and a timer. In five minutes, the explosive device will detonate. In this situation, if we ask whether Mary can open the safe, we may waver, even if we know that she has done that in the past and efficiently. We do not know whether she can do it in five minutes. The bifurcation between high-stakes and low-stakes situations and varying truth conditions can be transferred from knowing-that to knowing-how. And this seems to support the lack of a rigid division between knowing that and knowing how.

\subsection{Knowing how and Igor Douven's "The pragmatics of belief"}

Another testing bed for the assimilation of knowing how to knowing that is Igor Douven's (2010) "The pragmatics of belief." Igor Douven proposes that when we store a belief (in the form of an assertion or a sentence or a thought), we avoid storing it together with inferential augmentations that may lead us later to remember something that was not the case. This is called epistemic hygienics. A vivid example that comes from that paper is the reference to Gettier's problem. Suppose I know that $p$. Then, even if I can infer ' $p$ or q' from ' $p$,' it will not do to store in memory ' $p$ or q' if that is going to create trouble later, leading me to believe something that is false or unjustified. We may remember that which creates havoc in Gettier's problem is the shift from ' $p$ ' to 'p or q.' Keeping in memory 'p or q' when one believes 'p' creates trouble, as that may lead to an apparently justified belief that happens to be true.

The Principle that will avoid us many problems in the future is the following:

Epistemic Hygienics (EH): Do not accept sentences that could mislead your future selves. 
Other interesting examples by Douven are the following:

(10) Peggy's car is blue;

(11) Peggy's car is bluish.

Now, it is clear that if Peggy's car is blue, it is also bluish (blue being a stronger gradation of bluish). However, if one commits to memory "Peggy's car is bluish" when one believes that it is blue, one will commit to memory a piece of information that will mislead one's future self. Igor Douven compares memorizing or committing to memory to writing notes that will be of use to our future selves (e.g., "Turn off the gas"). If memories are like notes, we should avoid writing notes that mislead our future selves.

Igor Douven's paper is of great importance not only to epistemology but also to pragmatics. He shows that pragmatics and epistemology are intimately connected. While Igor Douven's story can be interpreted in the light of more general principles of cognition (a memory that is misleading obviously is a case in which a believed assumption is more costly than beneficial in terms of cognitive effects; positive cognitive effects being those that put me in touch with reality, not those thar drive me away from it), I cannot do this in this paper. I confine myself to asking the innocent question whether the pragmatics of belief also applies to knowing how (knowing entailing belief). Here, another crucial question arises: Does knowing how involve belief? Here, the treatment of knowledge by Williamson may come to our aid. While all or almost all philosophers insist on the fact that belief is more basic than knowledge, Williamson (2002) insists that knowledge is more basic than belief. The case of knowing how seems to attest that he is correct. One who is skilled in tying a knot may have no beliefs in how to tie a knot. He simply knows a practice. Of course, he must minimally believe that there is a way of tying a knot.

Returning to the pragmatics of belief, it is useful to choose an example in which a strategy and not a skill is involved. Consider the case in (12), which happens to be true:

(12) John knows how to reach Trafalgar Square in five minutes.

Surely, then, he knows how to reach Trafalgar Square in six minutes; in 10 minutes, in an hour.

Suppose that he was asked whether he can reach Trafalgar Square in five minutes, John ponders on the answer that yes he can do it. Then he ponders on the logical consequences of this. He arrives at the conclusion that he can reach Trafalgar Square in 10 minutes. He can also reach Trafalgar Square in 100 minutes. Suppose that, taken by the enthusiasm due to his logical deductive abilities, he goes on computing the answers to all the least stringent questions. Then he may forget the answer with which he started, which answered the 
question whether he could reach Trafalgar Square in five minutes. Igor Douven's epistemic hygienics will thus do some work in preventing John from memorizing all the logical consequences of his answer, which, if pursued in an endless line, will distract him from keeping his answer in mind.

So the answer is "yes," knowing how obeys Igor Douven's epistemic hygienics. Thus the case for a dichotomy between knowing how and knowing that is made weaker.

\section{Pragmatic intrusion}

Pragmatic theory (usually) deals with inferential phenomena that are intentional. On the one hand, a speaker gets a message across by using nonlinguistic means (or by combining linguistic means with features of the context that point interpretations in the right direction). On the other hand, a hearer is busy trying to retrieve the speaker's intention. Communication must be essentially seen as a matter of projecting and recovering intentionality through the multiple clues, linguistic and otherwise, disseminated by the speaker and available to the hearer. The hearer uses a number of clues to get across her intention, aware that the hearer will use them for recovering her intention. While Grice's project confined itself to recovering and studying conversational implicatures (inferences that are mainly cancellable, reinforceable, non-conventional and calculable), neo-Griceans (e.g., Levinson 2000) and Relevance Theorists (Sperber and Wilson 2002; Carston 1999) recognized that more is at stake than conversational implicatures and that the same processes available for the projection and recovery of conversational implicatures can be put to use in the recovery of explicatures, inferential contributions (or augmentations) that make an utterance truth-evaluable. Relevance theorists ponder on the issue of the truth-evaluability of sentential meanings, and come to the conclusion that sentential meaning is mainly underdetermined. In other words, were we to know ONLY what a sentence means, we would know little of what is being communicated, and the sentence would not be truth-evaluable (in many cases), simply because many other elements of a pragmatic kind enter into truth-evaluation. I have written about this in Capone $(2006,2008,2009)$ by exploring the issue of whether the pragmatically obtained elements of explicatures are cancellable or not. My main conclusion is that explicatures are NOT cancellable. This is an assumption that can be put to use in this paper on knowing how and pragmatic intrusion. I will not dwell on pragmatic intrusion here, because the reader has the opportunity to read about it elsewhere; however, I will produce a number of examples that have been taken to represent cases of pragmatic intrusion. Consider the case in which Mary is asked whether she would like to join for breakfast and she replies, "No thanks; I have already had breakfast." Clearly, 
she does not mean that she has had breakfast, say, on the previous day or a week ago; presumably she means that she has had breakfast on the morning of the invitation. This makes her contribution relevant to the previous invitation. Similarly, if someone asks you whether you have turned the gas off, she presumably intends to ask you NOT whether you turned the gas off 10 days ago, but a few minutes ago, say before leaving the house. One of the most celebrated cases of pragmatic intrusion is the following one by Carston: "It is better to meet the love of your life and get married than get married and meet the love of your life." ${ }^{3}$ Now, clearly settling temporal specifications into utterance interpretation is of importance in the evaluation of the utterance. "Better" requires that the two propositions compared be different, but UNLESS we specify (by free enrichment) the temporal specifications inside each sentential fragment, we either come up with a sentence that is potentially false or with a sentence whose truth-conditions are radically underdetermined and about which we cannot say whether it is true or false. Various authors have written about pragmatic intrusion. There is no space here for a review; however, see Capone 2006 for a review; also Claudia Bianchi 2001.

Pragmatic intrusion, in the case of "knowing how" occurs on a heavy contextual basis. Depending on what the context is, you must choose a specific modal, a "de re" interpretation or the quantifier "some" (rather than "all"). I have argued elsewhere that explicatures (at least actual explicatures) are not cancellable. This is strong proof that the explicature is a crucial contribution to what is said, as it contributes a layer of truth-conditional meaning.

Suppose you are interested in Mary's know-how because you want to carry out a certain job, such as opening a safe. Then it will not be indispensible to know whether Mary knows all ways to open the safe. One way is sufficient. We are not interested in exhaustive knowledge. Furthermore, in this situation, I am not interested in knowing whether Mary knows how one would open the safe, but in I am interested in knowing whether she knows some way for her to open the safe. I am not interested in knowing whether she has seen the procedure effected in the past, but in whether she has herself effected the procedure. In addition to that, I am interested in whether there is a way w such that she can open the safe with w. I am not interested in a modal such as 'must.' In other words, I leave her free to choose one way or the other, in case she knows more ways to open the safe.

\subsection{On the uses of "knowing how"}

What does one communicate when one says (13)?

(13) John knows how to fix the bike.

Is it different from what one says through (14)? 


\section{(14) John knows how Napoleon lost at Trafalgar.}

Intuitively, one feels that (13) is connected with expertise, as John has the expertise to fix the bike, even if he may not be able to articulate his expertise apart from pointing to his actions "This is the way I do it."

On the contrary, we have a feeling that (14) attributes to John articulated knowledge, which he may be able to articulate through a series of answers.

The question is even more complicated, as there are contexts in which the speaker's meaning is ambivalent, pointing both to expertise and to articulated knowledge (Damschen 2009). Consider, in fact, (15)

(15) John is a driving instructor. He knows how to drive.

Unlike an ordinary driver, not only does John know the technique involved in driving cars, but he can also articulate it through answers to questions by the learners. He must be able to teach learners, not only by pointing to the way he does it (This is how you must do it!), but by giving articulate answers to questions and by explicit teaching.

So, it is clear from the start that we are faced with an ambiguity and even with cases in which both readings are possible simultaneously (the two readings not being mutually exclusive). Possibly we are faced with an interpretative ambiguity. Since one of the explicit aims of pragmatic theories is to avoid semantic ambiguities (see Jasczolt 1999), from the start we opt for an interpretative ambiguity, which means we must aim at providing a logical form, which, by interacting with contexts, furnishes specific interpretations.

It is very instructive to consider an asymmetry pointed out by Snowdon (2003), between knowing that and knowing how.

John knows that $\mathrm{p} \rightarrow$ I know that $\mathrm{p}$

NOT: John knows how to $\mathrm{p} \rightarrow$ I know how to $\mathrm{p}$

I take $\rightarrow$ to be a symbol of entailment.

Actually the phenomenon should be described with a greater number of details.

A person who utters "John knows that p" is committed to knowing that John knows that $\mathrm{p}$. Since that person knows the obvious consequences of what she knows, she also knows that $p$, given the fact that if John knows that $p, p$ is true.

The asymmetry pointed out by Snowdon (2003) should remind us that differences exist. However, there are similarities too.

One such similarity, it should be stressed, is that "knowing how" can be communicated. In these cases, it behaves like "knowing that." Knowledge can be transmitted through speech acts, if the proposition known is not yet known to a third person and is deemed to be of use to her (say, it bears on a question that is of crucial importance to her either because she asked a question or 
because her behavior evinced eagerness to know a certain fact). One can say things such as:

(16) John taught me how to drive a bike.

(17) John learned how to ride a bike from Mary.

(18) John told me how to cook lasagna.

(19) John explained to me how to do the exercise.

(20) He taught me how to cook lasagna, and I remember well.

Depending on the scenarios in which these sentences are used, they may implicate that the way one learned or was taught was a verbal way. Words like "teach," "tell," and "explain" all involve the use of explicit instructions, maybe combined with showing. They strikingly contrast with "show," which involves non-verbal ways of teaching. "Learn" is perhaps neutral between learning by being taught through verbal instruction and learning by being shown how one does something.

There are uses of "knowing how," however, which are very different or look very different from "knowing that":

(21) John knows what being operated on is like;

(22) John remembers what falling down the stairs is like;

(23) John imagines what falling down the stairs is like;

(24) John tried to explain to me how it hurts to fall down the stairs.

What is known in these cases is an inner experience, which cannot be communicated or can only be communicated partially.

There are uses of "knowing how," which are odd, probably because knowing how involves explicit instruction, practice, and ability.

(25) John found out how to cook lasagna.

(26) John guessed how to cook lasagna.

(27) Mary knows in part how to cook lasagna.

If John was shown two cards, each describing a procedure for cooking lasagna, and just tossed a coin to guess which card is right, he would not exhibit knowledge that this is the right procedure for cooking lasagna. John's finding out how to cook lasagna is strange and must be interpreted as saying that John found the instructions how to cook lasagna (but he need not know how to cook lasagna, because he is not good at following instructions). Example (27) is used to support the distinction between knowing how and knowing that. It is claimed that one can have partial knowledge that, but not partial knowledge how. It seems to me that things are the other way around. One cannot have partial knowledge that, but one can have partial knowledge how. Consider, in fact, a worker who is instructed on how to execute a procedure; being late, he will be taught the rest of the procedure the day after. In this case, he has partial 
knowledge how, which will be developed into full knowledge-how when certain other skills will be integrated.

It has long been debated, since Ryle (1949), whether knowing how involves ability. Surely if I know how to ride a bike, I can ride a bike. However, the question to ask is whether this inference is an entailment or an implicature. Implicatures (in particular, potential implicatures) are defeasible, entailments are not (cases in which entailments are defeated are cases of loose usage). The philosophical literature is adamant on this. Snowdon argues convincingly that, while in many cases, if one knows how to $\mathrm{p}$, one can $\mathrm{p}$, this is not always the case. In particular, ability is neither a necessary nor a sufficient condition for knowing how to $\mathrm{p}$ (see also Bengson 2009). The standard examples discussed by Snowdon are cases like the following:

I know how to ride the bike. However, I have just had an accident and I have broken my leg. Thus, it appears that I cannot ride the bike. Nevertheless, I still how to ride the bike. When I recover, I will ride the bike again without any problems.

Various authors recognize that while ability is neither necessary nor sufficient for knowing how, in many cases when one says:

(28) John knows how to cook spaghetti.

it is implied that he can cook spaghetti.

It has been proposed that this is a conversational implicature. Surely this must be the case, given that conversational implicatures are non-monotonic inferences, and may arise standardly (standard implicatures). It is our world knowledge that licenses the "ability" implicature when one says ' $\mathrm{X}$ knows how to p.' We know that, if there are no special impediments, knowing how ipso facto creates the ability to do $\mathrm{p}$. In other words, we are empowered to do $\mathrm{p}$ by our knowledge on how to $\mathrm{p}$.

The implicature that one can do things becomes an explicature when knowing how has to be put to use. Suppose I am interested in whether John knows how to open the safe. Then I am not only interested in knowing whether John knows a procedure, but whether he has ever applied that procedure in the past. Depending on the context, the ability explicature becomes consolidated, and it may even become hard to cancel.

\subsection{Rumfitt and "savoir + infinitive": Toward a pragmatic story}

Rumfitt (2003) proposes a strong objection to Stanley and Williamson. He considers a wide range of languages in which "knowing how" is expressed through a construction of the type "savoir + infinitive" (e.g., French, Italian, Russian). It appears that there is a difference between 
(29) Giovanni sa nuotare

(lit. John knows to swim)

and

(30) Giovanni sa come nuotare.

(John knows how to swim).

If well-formed at all, (30) seems to conform to Stanley and Williamson's semantic elucidation for knowing how (i.e., there is a special way w of swimming and Giovanni knows w). (30) is probably appropriate to situations in which one, out of a several, ways of swimming is suited to the situation (in that a particular goal is being pursued). One also has the feeling that (30) allows a continuation as in:

(31) John knows how to swim (to impress the examiners).

The materials in parentheses are supplied contextually through free enrichment. So summing up, one has the impression that "sapere nuotare" and "sapere come nuotare" have different meanings.

Stanley and Williamson can reply to Rumfitt that "savoir + infinitive," after all, is a "know-how" construction in so far as it is possible to analyze it as having a question word as part of pragmatic intrusion (free enrichment, presumably). But then the question arises why there should be such a marked difference between (29) and (30). A possible answer to this question-an answer that is favorable to Stanley and Williamson - is that there is surely a contrast between (29) and (30), but that is NOT a matter of semantic entailments, but a matter of explicature. Assuming that (29) and (30) have the same semantic/ syntactic structure, then the more prolix and more marked (30) triggers some explicatures (M-explicatures, according to Horn (2009), Levinson (2000), and Huang (2000)). According to a Relevance Theory perspective, given that the more explicit "come" would be associated with the same semantic readings, it would be more costly to the hearer to utter one more word; thus, to make this cost bearable, one would have to offset the processing cost with suitable contextual effects. Thus, "come" triggers a conversational inference that aims at completing the sentential structure with a purpose clause.

\subsection{Inferences in context}

When one examines the cases of knowing how, one may notice some differences among the following cases:

(32) John knows how to drive the car.

(33) John knows how to fix the bike. 
(34) John knows how to ride the bike.

(35) John knows how to cook lasagna.

(36) John knows how to persuade the coach to let him play.

(37) John knows how to teach a history lesson.

(38) John knows how to arrive to the office by the shortest route.

All these cases are similar; yet they involve different shades of meaning. In (32) we seem to be confronted with a case of (skill) know-how. However, if the sentence is embedded in a context in which a mother tells her son to ask for John's help in learning to drive the car, it is conversationally implied that her son should be ready to provide verbal instructions. Sentence (33) seems to implicate that John also knows how to find the tools needed to fix the bike. Example (34) seems to express a skill; however, if the sentence is situated in a context in which you are asking for help on how to use a professional bike, "bike" here is interpreted as 'professional bike,' and the sentence is promoted from describing a skill to describing competence which can be articulated through instructions. Sentence (35) may range between an interpretation according to which John is being attributed a skill (he knows how to cook lasagna by heart) and an interpretation according to which he is being attributed a source of knowledge (i.e., he knows how to cook lasagna; he has a cook book in the kitchen, and he resorts to that book when he needs to cook lasagna. Here "knows how" actually implicates, perhaps due to a loose usage, that one knows "where" to find a recipe). Line (36) implicates that John has worked out a strategy on how to persuade his coach to let him play. Example (37) may implicate that John has a special method for teaching a history lesson or that he has rehearsed a history lesson. Sentence (38) implicates that John is able to calculate the shortest route to his office. It is incredible that, in different contexts, "knowing how" sentences take on different shades of meaning, which are not expressed by semantics alone.

There are other types of pragmatic interpretations with knowing how sentences. Consider, for example, scope ambiguities, as in the following:

(39) John knows how to fix a bike.

(40) John knows how to ride a bike.

(41) John knows how to calm the dog.

(42) John knows how to fix every bike.

In (39) and (40), it is unlikely that the indefinite NP has scope over the verb of propositional attitude. Thus we exclude the interpretations:

(43) There is a bike: John knows how to fix it.

(44) There is a bike: John knows how to ride it.

The natural interpretations of (39) and (40) seem to be the following: 
(45) If there is a broken bike, John knows how to fix it.

(46) If there is a bike, John knows how to ride it.

In (41), "the dog" escapes the scope of the verb of propositional attitude and has scope over it. As Jaszczolt (1999) correctly insists, NPs tend to be correlated with "de re" readings by default. I have argued in Capone (2009) that this story must be coupled with an RT explanation. I cannot go into this here. Sentence (42) has different interpretations. If there is a domain of quantification that is salient, then "every" will be interpreted as quantifying over elements from that domain (see Stanley 2007). If there is no such domain present, then it will have a genuinely universal quantification reading. HOWEVER, it will not be understood that John knows how to fix every bike (at the same time). What is probably needed is a selection function that selects the variables individually, and NOT cumulatively.

For all $\mathrm{x}, \mathrm{x}$ a bike, John knows how to fix it (SEL FUNC one by one);

For all $\mathrm{x}, \mathrm{x}$ a bike, John knows how to fix them (SEL FUNC all at once).

Presumably bound variables must have formal properties that correlate with different selection functions.

World knowledge is what enables the speaker/hearer to have access to the most reasonable or plausible reading. It is implausible that one can fix all bikes at the same time. Thus, this interpretation is NOT selected. The default interpretation is the one that accords with socio-cultural defaults (see Jaszczolt 2005).

There are other interpretation problems concerning "knowing how" interpretations. Let us assume that part of the story of knowing how utterances is that they are interpretable in the following way:

(47) John knows how to ride the bike.

(48) John knows that there is a way of riding the bike w and this is a way for him/for one to ride the bike.

The choice between one interpretation or the other is not trivial, and obviously depends on the context of utterance. A certain context of utterance will favor an interpretation rather than the other. However, one gets the impression that the default reading is (49):

(49) John knows that there is a way of riding the bike w and this is a way for him to drive the bike.

Presumably, the reading that has greater contextual implications (cognitive effects) wins. While in the majority of cases there is a coincidence between the way one rides the bike and the way John rides the bike, we are describing the situation from John's perspective, not from everyone else's perspective; thus it 
is natural that John has developed a way to ride the bike that accords with his natural inclinations. This is clearer in the following example:

(50) Alessandro knows how to drive the car in an Italian speedway.

Italian speedways are such that when there is a car from an incoming road, you either need to slow down in order to avoid accidents or you drive in the left lane, in order to avoid an accident. Surely this is an idiosyncratic way of driving. But Alessandro has developed his personalized way of driving. I assume that the natural interpretation of (50) is that Alessandro has his own way of driving in an Italian speed way. This is the interpretation that has richer cognitive effects and the one that conforms to Alessandro's perspective.

One further problem is the interpretation of the deontic modal.

(51) John knows how to fix the bike.

is equivalent to

(52) John knows that there is a way w and that is the way to fix the bike.

Roughly means (53):

(53) John knows that there is a way w and w is the way he can fix the bike.

Rather than

(54) John knows that there is a way w and w is the way he must fix the bike.

It is a matter of pragmatics that "can," rather than "must" is chosen. "Can" involves a greater space of freedom than "must." One assumes that activities like fixing bikes, etc., are done according to free will, and not under coercion. Again, it is socio-pragmatic defaults that are at work here.

Another interesting interpretative problem is whether one should have one of the following interpretations of, say, (55).

(55) John knows how to arrive at Trafalgar Square in five minutes.

(56) John knows some way $\mathrm{w}$ and $\mathrm{w}$ is a way he can reach Trafalgar Square in five minutes.

(57) John knows all ways w such that John can reach Trafalgar Square through w.

It appears philosophers prefer the interpretation (56). Again socio-cultural defaults are at work here. It is rarely the case that one knows all ways to do $\mathrm{p}$ and to know how to do p; it suffices to know one way to do $p$, rather than all. The most stringent interpretation is thus discarded. One settles on "some" as a default.

There are other inferences to consider. There are implicit restrictions to knowing how claims. Consider, in fact, the following (from Hawley 2003): 
(58) John knows how to drive (American cars).

(59) She knows how to drive (European cars).

(60) She knows how to cook (for an informal dinner).

(61) She knows how to cook (as a chef in a restaurant).

In all these cases, the context of utterance restricts the truth-conditions of the utterance. Contextualism can provide an explanation for why there can be so much variation in the truth-conditional import of the utterance. In all of the cases above, there is a restriction on the truth-conditional claim; this restriction is implicit and must be inferred pragmatically. Typical scenarios and situations of use can provide the materials for the pragmatic restrictions. Of course, one might reply (à la Cappelen and Lepore 2005) that one must then allow for an unlimited number of pragmatic increments. Sentence (58) could mean

(62) John knows how to drive in a Sicilian speedway.

(63) John knows how to drive in a chaotic traffic.

(64) John knows how to drive among drunk people.

(65) John knows how to drive a scooter.

I agree with Cappelen and Lepore that there can be many (even too many) contextual increments. But this does not make contextualism less appealing, provided that we know how to combine the basic sentential meanings with the contextual variables that lead to possible increments.

\subsection{A unified treatment of knowing how: Pragmatic intrusion?}

It has been claimed that knowing how utterances are characterized by an interpretative ambiguity. They are sometimes understood as describing abilities or skills; they are sometimes taken as describing knowledge of ways one can do p. Surely, there are a number of cases in which "knowing how" sentences appear to describe skills. The blacksmith has mastered a certain skill. He need not be able to articulate his knowledge, since many of the operations he executes are automatic. However, John who knows how to reach Trafalgar Square in five minutes does not have a skill. He was able to perform a calculation and to work out the shortest route to Trafalgar Square. He is able to say that w is the way he knows to arrive at Trafalgar Square in five minutes. He is also able to say why he chose w rather than w. This is not a skill or an ability. This is real knowledge.

Given this clear bifurcation in the uses of knowing how, one can hypothesize that the different uses are based on a single logical form ${ }^{4}$ :

(66) John knows ... how to p.

which is then pragmatically enriched to 
(67) John knows the answer to the question how to $\mathrm{p}$.

(68) John knows the technique how to $p$.

This amounts to claiming that (66) is a fragmentary semantic schema, to be enriched in context. Certain contexts promote skill interpretations; other contexts promote knowing the answer to the question whether $\mathrm{p}$ interpretations.

Another solution might be to follow Stanley and Williamson up to a certain point. At some point, Stanley and Williamson claim that the way in which one can $p$ is presented to the speaker/hearer through a practical mode of presentation. But this is clearly suitable to skills, not to know-how that is theoretical. Furthermore, we should distinguish between a practical and an indexical mode of presentation. The indexical mode of presentation is of use in cases like the following:

(69) John showed me how to fix the bike and I learned it.

For this example to work, John, rather than explaining how to do things, showed the hearer how to fix the bike, presumably saying, "This is the way to do it." This is not only a practical mode of presentation, but an indexical mode of presentation.

Now, I am favorable to having a unitary logical form like:

(70) John knows the answer to the question how to fix the bike.

One can, in fact, enrich this logical form by making use of a practical mode of presentation. This surely is more compatible with the situation in which both a practical and a theoretical mode of presentation is involved. Consider again the situation in which one says

(71) John knows how to drive the car.

implying that, since John is a driving instructor, he has both articulate knowledge that he can teach and practical knowledge that he can show. In this case, it is not clear given the logical form

(72) John knows ... how to drive the car.

how to arrive at the multiple interpretation (skill and articulate knowledge). Surely (73) is a bit far-fetched:

(73) John knows the answer to the question how to drive and the technique how to drive.

However, (74) is not:

(74) John knows that there is a way w in which he can drive the car.

$\mathrm{W}$ can be presented through a practical or theoretical mode of presentation; but there is nothing to prevent the speaker from using and expecting the hearer to infer a double mode of presentation of this way of driving. 
Why is (73) far-fetched and implausible? I assume that a reason why (73) is implausible is that it says that John knows two (distinct) things, and this does not accord with our understanding of daily use, while (73) can be interpreted as meaning that John knows one thing, which may be presented to him in different ways, according to the demands of context.

\subsection{A comparison between the pragmatics of knowing how and the pragmatics of propositional attitude reports}

Ideally, we would expect the pragmatics of knowing how and the pragmatics of propositional attitude reports to behave similarly. Let us remind our readers of my treatment of the pragmatics of belief reports in Capone (2008). There, I established some hidden constituents as a result of free enrichments. In particular, I posited some null appositives, attached to the clause of belief reports. Schematically, this amounts to the following:

(75) John believes that [Mary is in Paris] [Mary is in Paris] APP

The apposition, attached to the sentential constituent of the that-clause, makes it necessary that the semantic referents associated with "Mary" and with "Paris" in the structure of the thought or belief attributed to John should be glued with phonetic forms such as "Mary" and "Paris," which explains why substitution of identicals is blocked inside belief reports. In Capone (2008), I exposed a pragmatic story according to which the principle of relevance is involved in enriching the structure of (75) by adding an apposition clause. Such a story was based on cognitive effort, and assumed that, if a speaker bothered to use names in order to talk about referents in reporting a thought of John, then he had a reason to do so - this reason being that the names figured as parts of John's thoughts. Whether this story has to be amended or amplified is another matter, which I will not investigate here.

The question I am interested in is whether the pragmatics of knowing how works in a similar way. And the answer is that it doesn't exactly work in the same way, attributing to John knowledge of a way of doing an action. In fact, we have not said anything on whether the way of doing the action is outside or inside the scope of "know." One possibility is that it is outside the scope of "know." We, thus, accept the idea that, on a given interpretation, an utterance of "John knows how to ride the bike" amounts to:

(76) There is a way w, such that John knows how to ride the bike in way w.

Now, this logical form explains why, on some occasions, knowing how utterances are interpreted in a transparent way. Of course, the possibility remains open that the quantifier in 'There is a w . . ' can occur inside the scope of "John knows that" and, in this case, opacity is created, which justifies the consider- 
ations of those who posited opacity as part of knowing how structures. But now, if there is an ambiguity between a quantifier being outside the scope of "know" and a quantifier being inside the scope of "know," it is clear that my pragmatic story works well when the opaque reading is chosen, but NOT so well when the transparent reading is chosen. I suggest that we go for a bifurcation. When the opaque reading is chosen, then, in the same way in which belief reports could be equipped with null appositions through pragmatic intrusion (specifically free enrichment), a null apposition can be attached to $\mathrm{w}$, and this apposition would amount to a mode of presentation of $\mathrm{w}$. We assume that a practical mode of presentation of $\mathrm{w}$ is provided by default, given that a practical mode of presentation is often a firmer way of teaching one how to execute a procedure, since showing a procedure provides all or most of the information that could be provided through a linguistic articulation of the way in which something can be done, but things do not work all the way around. In other words, it is not the case that a linguistic articulation of the way something can be done will be able to express all the information which one can furnish by a practical mode of presentation (by giving an example of the action).

But if this story works for the opaque reading, this story should also work for the de re reading, since even outside the scope of a verb of knowledge, a way of doing something can be enriched by free enrichment through an apposition structure and a practical mode of presentation can be chosen on the grounds that it is necessarily more informative than a linguistically articulated mode of presentation.

We have seen that the generalized implicature story is only part of the full pragmatic story. Generalized implicatures must, in fact, be tailored to specific contexts and, therefore, it is not unusual that a certain implicature may be aborted in favor of an alternative interpretation. Examples (32)-(38) seem to prove that contextual considerations must be accommodated when one enriches the logical form of a specific knowing how utterance.

So, we have abandoned the simplistic assumption that generalized implicatures are selected despite the context or regardless of the context of utterance. We only retain the weaker view that generalized implicatures are triggered by default and are promoted to actual interpretation only if the context allows them (in other words if the context filters them in). If the context filters them out, then interpretation must follow a procedure in which various steps of reasoning are involved in selecting the favored interpretation.

\section{Conclusion}

Devitt (forthcoming) argues that epistemology should be divorced from linguistic considerations as Stanley and Williamson's considerations are mainly 


\section{Alessandro Capone}

based on linguistic considerations, but NOT on consideration of metaphysical issues. Now, while surely there are reasons for Devitt's assertion, this paper mainly shows that philosophy and pragmalinguistic considerations are deeply entangled. When matters of inference are considered, it is also worthwhile considering pragmatic intrusion. There are reasons to believe that almost all questions that pertain to knowing how can be analyzed with reference to pragmatic intrusion - that being a pervasive feature of human communication. Given what Igor Douven says about the pragmatics of belief, we are not surprised that knowledge, as well as belief, is strictly connected with the notion of communication and that many of the arguments that pertain to the sphere of epistemology can be illuminated by the tool of pragmatic intrusion.

\section{Notes}

1. Thanks are due to Igor Douven, E. Lepore, Michel Seymour, Neil Feit, Jacob L. Mey, Yan Huang, and Timothy Williamson for stimulating these considerations. All errors are my own.

2. In a later version of this paper (in press), Stanley cites Higginbotham (1993).

3. This example is originally Cohen's (1971).

4. Brogaard (2009) leads us in this direction, although he is not specific about pragmatic intrusion and what kind of underdetermined logical form is needed.

\section{References}

Alter, Torin. 2001. Know-how, ability and the ability hypothesis. Theoria 67(3). 229-239.

Annette, John. 1996. On knowing how to do things: A theory of motor imagery. Cognitive Brain Research 3. 65-69.

Bengson, John \& Marc Moffett. 2007. Know-how and concept possession. Philosophical Studies 136. 31-57.

Bengson, John, Marc Moffett, \& Jennifer Wright. 2009. The folk on knowing how. Philosophical Studies 142(3).

Bianchi, Claudia. 2001. La dipendenza contestuale: Per una teoria pragmatica del significato. Napoli: Edizioni Scientifiche Italiane.

Blakemore, Diane. 1995. Relevance theory. In Jeff Verschueren (ed.), Handbook of pragmatics manual. Amsterdam: John Benjamins.

Brogaard, Berit. 2009. Knowledge-How: A unified account. In J. Bengson \& M. Moffett (eds.), Knowing how: essays on knowledge, mind and action. Oxford: OUP.

Capone, Alessandro. 2006. On Grice's circle. Journal of Pragmatics. 38. 645-669.

Capone, Alessandro. 2008. Belief reports and pragmatic intrusion: The case of null appositives. Journal of Pragmatics 40. 1019-1040.

Capone, Alessandro. 2009a. Are explicatures cancellable? Intercultural Pragmatics 6/1: 55-83.

Capone, Alessandro. 2009b. Further considerations on the cancellability of explicatures. RASK: International Journal of Language and Communication 30. 2009.

Capone, Alessandro. 2009c. Default semantics and the architecture of the mind. Submitted to the Journal of Pragmatics.

Capone, Alessandro. 2010. On the social practice of indirect reports. Journal of Pragmatics 42. $377-391$. 
Capone, Alessandro. 2010. "Between Scylla and Charibdis": The semantics and pragmatics of attitudes 'de se.' Intercultural Pragmatics 7(3). 471-503.

Capone, Alessandro. Forthcoming. What can modularity of mind tell us about the semantics/ pragmatics debate? Australian Journal of Linguistics.

Cappelen, Herman \& Ernest Lepore. 2005. Insensitive semantics: A Defence of Semantic Minimalism and Speech Act Pluralism. Oxford: Blackwell.

Carr, David. 1979. The logic of knowing how and ability. Mind 88(351): 394-409.

Carr, David. Knowledge in practice. American Philosophical Quarterly 18(1). 53-61.

Carston, Robyn. 1999. The semantics/pragmatics distinction: a view from Relevance Theory. In K. Turner (ed.), The Semantics/Pragmatics Interface from Different Points of View, 85-125. Elsevier: Oxford.

Carston, Robyn. 2002. Thoughts and utterances. The pragmatics of explicit communication. Blackwell: Oxford.

Cohen, L. J. 1971. Some remarks on Grice's views about the logical particles of natural language. In Y. Bar-Hillel (ed.), Pragmatics of Natural Language, 50-68. Reidel: Dordrecht.

Damschen, Gregor. 2009. Dispositional knowledge-how versus propositional knowledge-that. In G. Damschen, R. Schnepf, \& K. Stueber (eds.), Debating dispositions. Issues in metaphysics, epistemology and philology of mind. Berlin: De Gruyter.

Davis, Wayne A. 2007. How normative is implicature. Journal of Pragmatics 39. 1655-1672.

Davis, Wayne. 2010. Metalinguistic negations, denial, and idioms. Submitted to the Journal of Pragmatics.

De Rose, Keith. 2009. The case for contextualism. Oxford: OUP.

Devitt, Michael. 2010. Methodology and the nature of knowing how. Submitted to the Journal of Philosophy.

Douven, Igor. 2010. The pragmatics of belief. Journal of Pragmatics 42(1). 35-47.

Ninan, Dilip. 2009. De se attitudes: Ascription and communication. Philosophy Compass.

Douven, Igor. 2009. The pragmatics of belief. Journal of Pragmatics 42(1). 35-47.

Fabbri-Destro, Maddalena \& Giacomo Rizzolatti. 2008. Mirror neurons and mirror systems on monkeys and humans. Physiology 23. 171-179.

Fantl, Jeremy. 2009. Knowing how and knowing that. Philosophy Compass 3(3). 451-70.

Gettier, Edmund. 1963. Is Justified True Belief Knowledge? Analysis 23. 121-123.

Hawley, Katherine. 2003. Success and knowledge-how. American Philosophical Quarterly 40(1). 19-31.

Hawthorn, John \& Jason Stanley. Forthcoming. Knowledge in action. Journal of Philosophy.

Hetherington, Stephen. 2008. Knowing that, knowing how and knowing philosophically. Grazer Philosophische Studien 77. 307-24.

Higginbotham, James. 1993. Interrogatives. In K. Hale \& S. J. Kayser (eds.). The view from building 20. Cambridge, Mass.: MIT Press.

Higginbotham, James. 2009. On words and thoughts about oneself. USC: Los Angeles.

Horn, Laurence. 1985. Metalinguistic negation and pragmatic ambiguity. Language 61 (1). 121-174.

Horn, L. 2009. Implicature, truth and meaning. International Review of Pragmatics 1. 3-34.

Hornsby, Jennifer \& Jason Stanley. 2005. Semantic knowledge and practical knowledge. Proceedings of the Aristotelian Society 79(1). 107-130.

Huang, Yan. 2000. Anaphora. Oxford: OUP.

Jaszczolt, K. 1999. Discourse, Beliefs and Intentions. Elsevier: Oxford.

Jaszczolt, K. 2005. Default semantics: Foundations of a compositional theory of acts of communication. Oxford: OUP.

Katzoff, Charlotte. 1984. Knowing how. The Southern Journal of Philosophy XXII. 61-69.

Kiefer, Ferenc. 1998. Modality. In Jeff Verschueren \& Jan-Ola Östman (eds.). Handbook of Pragmatics, 1-36. Amsterdam: John Benjamins. 


\section{AUTHOR'S COPY | AUTORENEXEMPLAR}

\section{Alessandro Capone}

Koether, John. 2002. Stanley and Williamson on knowing how. Journal of Philosophy 99(6). 325 328.

Levinson, Stephen. 2000. Presumptive meanings: The theory of generalized conversational implicature. Cambridge, Mass.: MIT.

MacFarlane, John. 2009. Nonindexical contextualism. Synthese 166. 231-250.

Mellor, D. H. 1992. Nothing like experience. Meeting of the Aristotelian Society.

Poston, Ted. 2009. Know how to be Gettiered? Philosophy and Phenomenological Research LXXIX(3): 743-747.

Raymont, Paul. 1999. The know-how response to Jackson's knowledge argument. Journal of Philosophical Research XXIV. 113-26.

Roland, Jane. 1958. On "knowing how" and "knowing that." Journal of Philosophy 67(3). 379388.

Rosenfeld, Tobias. 2004. Is knowing how simply a case of knowing that? Philosophical Investigations 27(4). 370-379.

Rumfitt, Ian. 2003. Savoir faire. Journal of Philosophy 100. 158-166.

Ryle, Gilbert. 2000[1949]. The concept of mind. Chicago: Chicago University Press.

Salmon, Nathan, 1990. A Millian heir rejects the wages of sinn. In Anthony C. Anderson \& Joseph Owens (eds.), Propositional Attitudes, 215-248. The Role of Content in Logic, Language, and Mind. Stanford: CSLI Publications.

Schaffer, Jonathan. 2007. Knowing the answer. Philosophy and Phenomenological Research LXXV(2). 383-403.

Schiffer, Stephen. 2002. Amazing knowledge. The Journal of Philosophy 99(4). 200-202.

Sgaravatti, Daniele \& Elia Zardini. 2008. Knowing how to establish intellectualism. Grazer Philosophischen Studien 77(1). 217-261.

Sperber, Dan \& Deirdre Wilson. 2004. Relevance theory. In Laurence R. Horn \& Gregory Ward (eds.), The handbook of pragmatics, 607-632. Oxford, Blackwell.

Sherry, David \& Daniel Schacter. 1987. The evolution of multiple memory systems. The Psychology Review 94(4). 439-454.

Snowdon, Paul. 2003. Knowing how and knowing that: A distinction reconsidered. Meeting of the Aristotelian Society.

Stanley, Jason \& Timothy Williamson. 2001. Knowing how. Journal of Philosophy 98(8). 411-444.

Stanley, Jason. 2007. Language in context. Oxford: OUP.

Stanley, Jason. Forthcoming. Knowing (How). Nous.

Steel, Thomas. 1974. A puzzle about knowing how. Philosophical Studies 25(1). 43-50.

Young, Gary. 2004. Bodily knowing: Re-thinking our understanding of procedural knowledge. Philosophical Explorations 7(1). 37-54.

Young, Gary. 2009. Case study evidence for an irreducible form of knowing how to: An argument against a reductive epistemology. Philosophia 37. 341-360.

Wallis, Charles. 2008. Consciousness, context and know-how. Synthese 160. 123-153.

Wilson, Deirdre \& Dan Sperber. 2002. Truthfulness and relevance. Mind 111(443). 583-632.

Williams, John N. 2008. Propositional knowledge and know-how. Synthese 165. 107-125.

Williamson, Timothy. 2002. Knowledge and its limits. Oxford: OUP.

Williamson, Timothy. 1996. Knowing and asserting. The Philosophical Review 105(4). 489-523.

Winch, Christopher. 2009. Ryle on knowing how and the possibility of vocational education. Journal of Applied Philosophy 26(1). 88-101.

Zwicky, Arnold \& Jerrold Sadock. 1975. Ambiguity tests and how to fail them. In Kimball (ed.). Syntax and semantics. New York: Academic Press.

Correspondence address: alessandro.capone@unipa.it 